\title{
A contribuição da Revista Ciência \& Saúde Coletiva para os estudos sobre e gênero e saúde
}

\author{
The contribution of Journal Ciência \& Saúde Coletiva \\ to gender and health studies
}

Wilza Vieira Villela (https://orcid.org/0000-0002-6246-2716) ${ }^{1}$

Simone Souza Monteiro (https://orcid.org/0000-0003-2009-1790) ${ }^{2}$

Regina Maria Barbosa (https://orcid.org/0000-0002-3390-2137) ${ }^{3}$

${ }^{1}$ Departamento de

Medicina Preventiva,

Universidade Federal de São

Paulo. R. Borges Lagoa 1341,

Vila Clementino. 04038-034

São Paulo SP Brasil. wilza.

villela@gmail.com

${ }^{2}$ Instituto Oswaldo Cruz,

Fiocruz. Rio de Janeiro RJ

Brasil.

${ }^{3}$ Núcleo de Estudos de

População "Elza Berquó",

Universidade Estadual de

Campinas. Campinas SP

Brasil.

\begin{abstract}
This paper aims to explore C\&SC's contributions to gender and health studies. Therefore, mapping was carried out through the SciELO platform, using the terms gender, man/ men, woman/women, youth/youths, adolescent/ adolescents. A total of 164 papers were selected, categorized by year of publication, type of study, population, topics addressed, and method. The analysis of the material shows the journal's contribution to proposing themes that favor analyses from the gender perspective. Some productions reflect the most current discussions. However, the paucity of works on gender in life cycles and the intersectional approach suggests that the journal's proactive posture should be maintained to encourage gender analysis in other topics than sexual and reproductive health, masculinities, and gender violence against women.
\end{abstract}

Key words Gender, Collective health, Women, Men
Resumo Este artigo tem como finalidade explorar as contribuições da CÆSC para os estudos sobre gênero e saúde. Para tanto, foi realizado um mapeamento por meio da plataforma da revista no SciELO, utilizando os unitermos gênero, homem/homens, mulher/mulheres, jovem/jovens, adolescente/adolescentes. Foram selecionados 164 artigos, categorizados em função do ano de publicação, tipo de estudo, população estudada, temas abordados e método. A análise do material aponta a contribuição da revista ao propor temas que favorecem análises na perspectiva de gênero. Algumas produções traduzem discussões atuais. Entretanto, o pequeno número de artigos sobre gênero nos ciclos de vida e desde uma abordagem interseccional sugere que a postura proativa da revista deve ser mantida para estimular análises de gênero em outros temas que não a saúde sexual e reprodutiva, as masculinidades e a violência de gênero contra mulheres.

Palavras-chave Gênero, Saúde coletiva, Mulheres, Homens 


\section{Introdução}

O termo gênero aparece na literatura acadêmica a partir dos estudos feministas, como ferramenta analítica para explicar a dinâmica social que produz e naturaliza a opressão e a dominação das mulheres. Tem como um dos marcos referenciais o trabalho da antropóloga Gayle Rubin que cunha a expressão "sistema sexo gênero" para referir "os arranjos por meio dos quais uma sociedade transforma a sexualidade biológica em

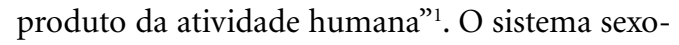
gênero divide os seres humanos em duas categorias - as mulheres e os homens, que passam a ser distinguidos não apenas por sua anátomo-fisiologia reprodutiva, mas por atributos de ordem social, comportamental e psicológica. Construídos como opostas e hierárquicas, as ideias de feminilidade e masculinidade organizam as práticas cotidianas em nível individual e coletivo, inclusive as relações amorosas e sexuais, já que o sistema sexo-gênero, pressupõe a heterossexualidade como norma ${ }^{2}$.

Em 1986 a historiadora Joan Scott afirmou que as relações construídas a partir da valorização diferenciada de características consideradas femininas ou masculinas, em detrimento das primeiras, são necessariamente relações de poder ${ }^{3}$. A autora acrescenta que a dinâmica de poder que funda as relações de gênero não se refere exclusivamente a trocas em âmbito interpessoal, mas se produz e reproduz histórica e culturalmente por meio de signos, símbolos e práticas sociais. Desta forma, o gênero marca as subjetividades de mulheres e de homens, determinando maneiras de pensar, sentir e agir numa dada sociedade que, de alguma forma, se refletem nas instituições e nas políticas $^{3}$. Embora dizendo respeito, em última instância, à opressão das mulheres, gênero opera no âmbito das relações entre mulheres e homens, nas relações das mulheres entre si, dos homens entre si e nas relações de todas as pessoas com as várias instituições sociais. Os modos como cada um se insere numa dada sociedade e vivencia seu corpo, seu sexo, seus sentimentos, sua identidade e sua própria inserção social são marcados pelo gênero. O gênero confere significados aos corpos e às individualidades, devendo ser considerado na análise dos processos sociais e políticos ${ }^{3}$.

Em 1990, a filósofa Judith Butler questionou o uso do termo gênero como categoria unívoca que desvela a opressão das mulheres. Para ela, distinções de classe social, pertencimento étnico, sexualidade e inscrições culturais conferem um grau de heterogeneidade entre as mulheres que deve ser considerado ${ }^{4}$. Em diálogo com as análises que abordam gênero como "a elaboração social da diferença sexual” - expressão pela qual o conceito de gênero se popularizou, dizendo respeito aos significados que o sexo assume em cada cultura -, Butler sugere uma lógica inversa. Seriam os processos sociais de atribuição de significados a corpos, práticas corporais e práticas sexuais, quer dizer o gênero, que instituiriam a diferença sexual ${ }^{5}$. Ademais, argumenta sobre a relativa independência entre corpo sexuado, gênero e desejo. Sendo a corporeidade e o desejo vivenciados pelo sujeito, estes não se submetem inteiramente ao gênero. $\mathrm{Ou}$ seja, mesmo que as formas de experimentar corpo e sexualidade sejam informados pelo gênero, estas também o desafiam, podendo afirmá-lo e transformá-lo a partir de performances individuais ${ }^{5}$. Gênero não determina sexo ou desejo, nem sexo determina gênero, embora sejam dimensões imbricadas.

Para a antropóloga Adriana Piscitelli, a aquisição de novos sentidos para o termo gênero não esmaece seu caráter político. Ao contrário, exige:

pensar não apenas nas distinções entre homens e mulheres, entre masculino e feminino, mas em como as construções de masculinidade e feminilidade são criadas na articulação com outras diferenças, de raça, classe social, nacionalidade, idade; e como essas noções se embaralham e misturam no corpo de todas as pessoas ${ }^{6}$.

Sob este ponto de vista, os estudos de gênero deveriam ampliar seu foco, buscando identificar como processos de dominação das mulheres se articulam a outros marcadores sociais da diferença. E, desse modo, produzem hierarquias e desigualdades não só entre mulheres e homens, mas entre grupos de mulheres e grupos de homens em função de raça/etnia, classe social, orientação sexual, religiosidade, faixa etária e outros atributos sociais. Essa perspectiva, de buscar a interseccionalidade entre diferentes marcadores sociais na produção das desigualdades, inicialmente cunhada por Crenshaw ${ }^{7}$, vem ganhando importância nos estudos acadêmicos ${ }^{8}$, contribuindo para diferenciar os estudos de gênero daqueles que tomam, de forma acrítica, mulheres e homens como seus objetos.

A potencialidade da categoria gênero para a análise de processos de produção de desigualdades sociais e das suas consequências para a saúde justifica a relevância da sua incorporação no campo da Saúde Pública, compromissado, em âmbito internacional ${ }^{9}$ e no Brasil, com o direito de todos à saúde ${ }^{10}$. Ao longo dos anos têm se avolumado evidências sobre as diferenças nos perfis de mor- 
bimortalidade entre mulheres e homens, nos seus comportamentos em relação à saúde e à doença e à procura e utilização dos serviços de saúde ${ }^{11}$. Em paralelo, tem sido apontado que essas diferenças, em parte, podem ser explicadas a partir da análise dos comportamentos e práticas considerados adequados para mulheres e homens, durante as fases da vida ${ }^{12}$. Isto significa dizer que as crenças e normas de gênero colaboram para a exposição de mulheres e homens a riscos desnecessários e podem ser obstáculos para a adoção de práticas preventivas e de autocuidado e o acesso a serviços de saúde. Ademais, podem interferir em processos de tomada de decisões que favoreçam a saúde ${ }^{13}$.

O reconhecimento por parte da Organização Mundial de Saúde (OMS), de que gênero é um dos determinantes sociais da saúde e que as desigualdades de gênero promovem desigualdades em saúde, acompanha o posicionamento histórico assumido na IV Conferência Internacional sobre População e Desenvolvimento (Cairo, 1984) de que essas desigualdades impactam, de forma negativa, o desenvolvimento sustentável no âmbito global ${ }^{14,15}$. Ainda nesta direção, a IV Conferência Mundial sobre as Mulheres, (Beijin,1995) ${ }^{16}$, reafirma o direito das mulheres à saúde, em especial à oferta de serviços de saúde sexual e reprodutiva e a uma vida sem violência. Assim, em 1997, a OMS recomenda que todas as políticas e práticas desenvolvidas pelos seus entes sejam marcadas pela perspectiva de gênero ${ }^{17}$, incluindo as ações para a prevenção e a mitigação das consequências da violência contra as mulheres.

Essa diretriz da OMS se traduziu no estímulo à elaboração de políticas públicas voltadas para a redução das desigualdades de gênero na saúde e ao desenvolvimento de estudos que pudessem lhes dar suporte. É recomendada tanto a desagregação de dados por sexo nas pesquisas de base populacional, quanto a construção de referenciais teóricos que contemplem a análise do impacto do gênero na vida cotidiana de mulheres e homens ${ }^{18}$. Considera-se ainda que a incorporação da perspectiva de gênero na saúde exige iniciativas em diversos níveis, desde a análise sistemática dos possíveis vieses de gênero em leis, políticas, programas e serviços de saúde, até a identificação das janelas de oportunidades proporcionadas por estes instrumentos e a implementação e a avaliação de respostas. Ademais, este esforço busca definir prioridades de pesquisa e alocação de recursos visando identificar como as relações de gênero moldam práticas sociais e os seus efeitos sobre a saúde ${ }^{11}$.
No Brasil, impulsionadas pelo movimento de mulheres, as ações públicas em saúde (governamentais e não governamentais) voltadas para enfrentar os efeitos das desigualdades de gênero sobre a saúde das mulheres se iniciaram em 1984, com o Programa de Atenção Integral à Saúde da Mulher (PAISM). Esse programa buscou romper com a perspectiva materno-infantil que orientava a organização dos serviços básicos de saúde para reivindicar um modelo de atenção capaz de considerar as distintas necessidades das mulheres ao longo da vida ${ }^{19}$. A implementação do PAISM enfrentou muitas dificuldades, mas suas propostas se fortaleceram com as Plataformas das Conferências de Cairo e de Beijing, já referidas. Sendo signatário de ambas, o governo brasileiro produziu vários instrumentos - planos, políticas e programas -, para que os acordos internacionais e as demandas da sociedade civil por equidade tivessem uma tradução institucional.

$\mathrm{O}$ ativismo de segmentos da sociedade civil, como ONGs, pesquisadores e acadêmicos e o diálogo desses atores com setores governamentais fomentaram a criação de instrumentos para cumprir os acordos estabelecidos. Assim, em 2004 foi elaborada a Política de Saúde para a População LGBT, contida no Programa Brasil sem homofobia; em 2006 é sancionada a Lei Maria da Penha que estabelece fluxos e linhas de cuidado para as mulheres vitimadas pela violência de gênero; em 2009 é instituída a Política de Atenção Integral à Saúde da População Negra. No mesmo ano é criada a Política de Atenção Integral à Saúde do Homem, impulsionada por médicos, a partir de análises dos perfis de morbimortalidade masculina ${ }^{20}$. Estas iniciativas têm se concretizado por meio de práticas nos serviços, ilustradas pela ampliação de ofertas em saúde sexual e reprodutiva e enfrentamento da violência contra as mulheres e suas consequências para a saúde ${ }^{21}$. A produção acadêmica sobre gênero e saúde igualmente se intensificou, abarcando diferentes temas, enfoques e perspectivas teóricas ${ }^{22}$.

O campo da saúde coletiva, por sua característica interdisciplinar e política ${ }^{23}$, é privilegiado para articular reflexões que, tendo como objeto aspectos do cotidiano de mulheres e homens e práticas dos serviços e instituições, irão problematizar como gênero determina a produção social da vida e da saúde. No Brasil, a Associação Brasileira de Saúde Coletiva, Abrasco, tem desempenhado papel de relevo na constituição e consolidação desse campo, sendo a Revista Cien Saude Colet, C\&SC, um dos seus principais porta-vozes. Por meio de suas publicações, tem 
participado dos debates que modelam a saúde coletiva brasileira. Comemorando os 25 anos de criação da Revista, este artigo objetiva apreciar a sua contribuição para os estudos de gênero na saúde.

\section{Metodologia}

Foi realizado um mapeamento e análise dos artigos voltados para a relação entre gênero e saúde publicados pela C\&SC ao longo desses 25 anos. Frente à polissemia do termo "gênero", somada à sua natureza política e à sua perspectiva de desnaturalização das diferenças entre mulheres e homens, o mapeamento proposto privilegiou os manuscritos que apresentassem, no delineamento, referencial teórico ou discussão, o reconhecimento de que os sujeitos ou processos estudados são atravessados por este determinante social. Não foram incluídos estudos que considerassem identidades sexuais sem uma discussão sobre gênero ou que tomassem os eventos referentes à saúde de mulheres e homens sem contemplar a dimensão do gênero na produção ou dinâmica do evento investigado.

A partir desta definição foi realizado um levantamento, por meio da plataforma SciELO, dos artigos com o termo gênero em qualquer índice (título, autor e assunto), da revista C\&SC, desde o primeiro volume, que resultou na identificação de 271 artigos. Busca adicional, utilizando os unitermos mulher/mulheres, homem/homens jovem/jovens e adolescente/adolescentes, identificou mais 22 trabalhos que satisfaziam aos critérios de inclusão.

Após leitura dos títulos e resumos foram excluídos os editoriais e os comentários de debate e os artigos em que o termo gênero não estava referido à diferença sexual ou quando esta referência se restringiu a aspectos biológicos sem abordar a inscrição cultural dos corpos femininos ou masculinos em relação ao evento estudado. Chegou-se a um total de 164 artigos que usaram explicitamente o termo gênero como dispositivo teórico ou analisaram seus dados a partir das determinações de gênero. Estes manuscritos foram categorizados segundo: tipo de publicação, abordagem metodológica, ano de publicação, temática central e população estudada. Para análise do material buscou-se identificar possíveis relações entre as categorias e as questões emergentes no campo da saúde coletiva.

Saliente-se que toda a seleção e classificação, especialmente quando orientada por uma cate- goria fluida como gênero, pode ser questionada. A opção de não incluir os unitermos criança(s) nos critérios de busca, de não esgotar todas as possiblidades de palavras chaves e de excluir trabalhos sobre identidades sexuais que não assumissem o recorte de gênero como pressuposto ou perspectiva de análise, pode ter deixado de fora algum trabalho relevante. A seleção e a análise dos artigos feita de forma independente pelas autoras buscou minimizar esses possíveis vieses. $O$ respeito da escolha dos autores sobre as palavras-chave ou uso do termo gênero foi outro cuidado, dado que a definição de um estudo como "de gênero" está prioritariamente vinculada ao olhar do pesquisador. Acreditamos que eventuais lacunas não interferiram na análise proposta de caráter eminentemente qualitativo.

Outro desafio é a classificação temática tendo em vista o entrecruzamento dos assuntos abordados nos trabalhos. A sexualidade, por exemplo, é parte importante da construção das masculinidades, das práticas em Saúde Reprodutiva e da Prevenção das IST/Aids. Da mesma forma, as políticas públicas permeiam as práticas dos serviços e dos sujeitos. Entretanto, o reducionismo dos processos classificatórios é inexorável. E, mais uma vez, o respeito à classificação temática escolhida pelo autor foi um critério útil. Por fim, há um reducionismo na análise, dado que um conjunto grande de artigos dificulta o diálogo com os fundamentos teóricos dos autores. Ademais, a opção por uma análise, privilegiando temas emergentes no campo da saúde coletiva a partir da perspectiva de gênero, pode ter obscurecido outras contribuições possíveis.

\section{Resultados}

O primeiro artigo incluído na seleção data de 1999. Em todo período analisado, a distribuição das publicações é irregular, variando de nenhuma em 2000, 2001 e 2007 a 26 em 2012. A abordagem de gênero está presente em números sobre violência, suicídio e envelhecimento, ao lado de artigos com temas livres. No entanto, os anos com maior volume de trabalhos com a perspectiva de gênero, coincidem com a publicação de números temáticos sobre assuntos mais permeáveis a este olhar como: a emergência dos homens como foco da saúde pública, a incorporação do gênero na saúde coletiva, o aborto e a Política Nacional de Atenção Integral a Saúde dos Homens. O Gráfico 1 apresenta o número de artigos com recorte de gênero publicados a cada ano. 


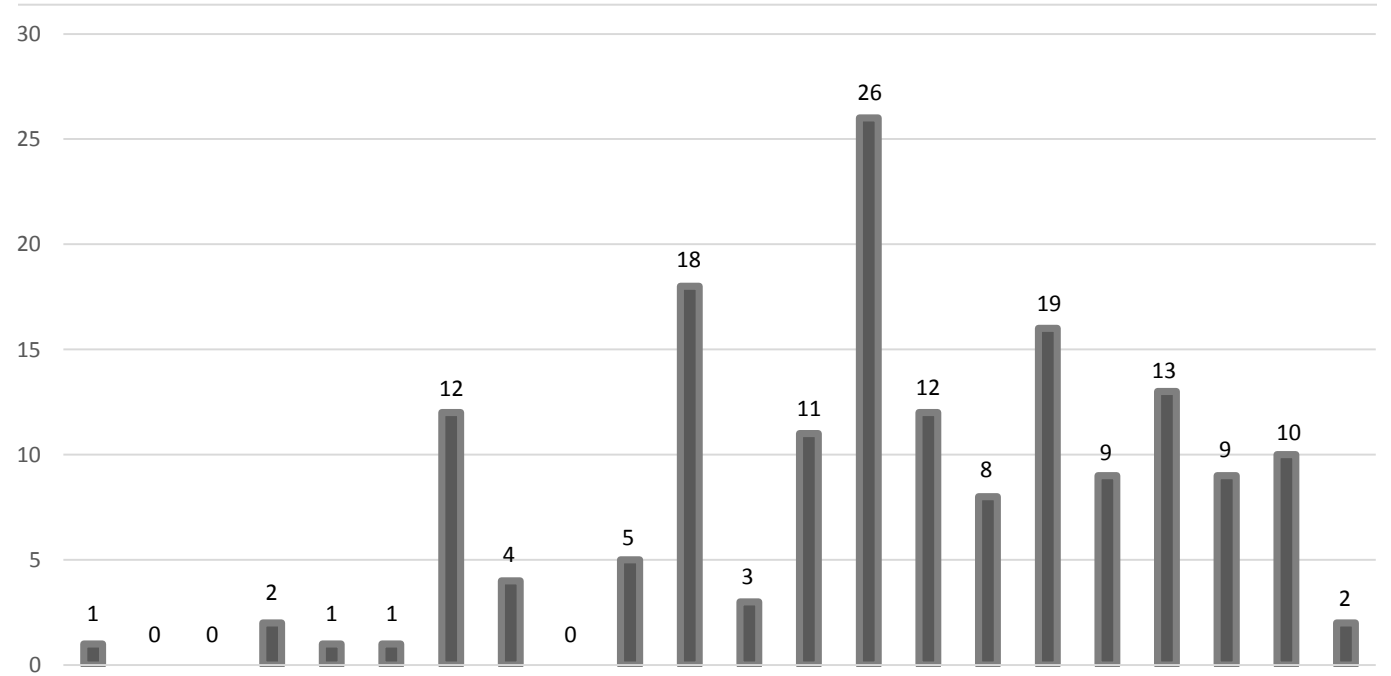

1999200020012002200320042005200620072008200920102011201220132014201520162017201820192020

Gráfico 1. Número de artigos com recorte de gênero publicados a cada ano na revista C\&SC.

Em relação ao tipo de publicação, predominam estudos empíricos com produção de dados primários (89/164), seguido de ensaios, textos de opinião, artigos de debate e entrevistas (29/164). Foram ainda identificadas análises de dados secundários (21/164) usando, em geral, bancos de dados dos sistemas de informação (SIM, SINAM, AIH registros hospitalares, boletins de ocorrência e outros) ou de pesquisas nacionais (PNAD, PENSE e outras). Doze manuscritos (12/164) basearam-se em análise documental (arquivos, normas técnicas, notícias de jornal e peças de mídia). Estudos de revisão (09), resenhas (04) completam o conjunto de publicações.

A população mais estudada (nos 134 manuscritos a que isto se aplica) é a de mulheres (37/134), incluindo mulheres da população em geral e aquelas com alguma especificidade, como profissionais do sexo, envolvidas no tráfico, portadoras de deficiência ou de agravos à saúde e que sofreram violência. A maioria dos trabalhos aborda mulheres em idade reprodutiva, apenas dois enfocam idosas e o mesmo número, adolescentes/jovens. Dentre os manuscritos que abordam homens (33/134), sete enfocam adolescentes ou jovens e um, idosos. Trinta (30/134) trabalhos incluem mulheres e homens, sendo quatro com pessoas idosas e doze com adolescentes ou jovens. Profissionais ou gestores também são objeto de trinta artigos (30/134). Um trabalho aborda a orientação sexual dos informantes, analisando seus resultados sob a ótica do gênero e outro utiliza a categoria gênero para discutir dados empíricos sobre pessoas transexuais. Em seis manuscritos há intenção explicita de articular determinações de gênero e outros marcadores de desigualdade, como raça/cor/etnia ou pobreza, numa perspectiva de interseccionalidade.

Os temas são variados, com predomínio daqueles relacionados à Saúde Sexual e Reprodutiva, como contracepção, prevenção do HIV/aids, violência obstétrica, $(35 / 164)$ e, principalmente, aborto (16/35). A violência de gênero contra mulheres (Violência Baseada no gênero, VBG) é tratada em 32 trabalhos; masculinidades e suas repercussões para a saúde dos homens também somam 32 produções. Sexualidade é tema central de 15 manuscritos e questões de saúde em geral, analisadas sob a perspectiva de gênero, somam 10. Trabalho (10), políticas públicas (07), saúde mental e uso de substâncias (07) são abordados e em menor frequência, a violência (04) questões de poder (04) e o envelhecimento (03).

A diversidade metodológica reflete a amplitude de temas e objetos, mas há um maior número de estudos com abordagens qualitativas, etnográficas ou não, apoiados por diferentes referenciais teórico-metodológicos. Registram-se 
trabalhos realizados nas cinco regiões do país, com maior concentração daqueles oriundos das regiões sudeste e sul. Há ainda uma contribuição de estudos internacionais. O Quadro 1 sintetiza os principais resultados deste mapeamento, baseados numa classificação elaborada pelas autoras levando em conta: tipo de estudo, sujeitos, temas e abordagem metodológica:

\section{Discussão}

$\mathrm{O}$ uso da categoria gênero, como dispositivo de análise dos processos humanos, refere-se a um deslocamento do biológico para o social. Assim, não surpreende a presença de trabalhos empíricos e teóricos sob esta ótica na revista C\&SC, dado que este alargamento da compreensão do humano é semelhante à ampliação do foco dos estudos em saúde para incluir além da doença, a produção da vida ${ }^{24}$, movimento que marca a constituição do campo da saúde coletiva no Brasil.

Como indicado no Gráfico 1, manuscritos produzidos sob a perspectiva de gênero estão presentes em vários volumes. Em especial nos que se referem a temas situados na interface com as ciências sociais e humanas ${ }^{25}$, como a violência, o suicídio e os ciclos da vida. No entanto, é inegável a importância dos números temáticos para dar destaque a assuntos cujo debate é re-

Quadro 1. Síntese dos resultados da revisão dos artigos com recorte de gênero publicados entre 1999 e 2020 na revista C\&SC.

\begin{tabular}{|c|c|}
\hline Tipo de estudo & $\mathbf{N}$ \\
\hline Empírico & 89 \\
\hline Teórico (ensaio/opinião/ debate, entrevistas) & 29 \\
\hline Análise dados secundários & 21 \\
\hline Análise documental & 12 \\
\hline Revisão & 9 \\
\hline Resenha & 4 \\
\hline Total & $164^{*}$ \\
\hline \multicolumn{2}{|l|}{ Sujeitos } \\
\hline Mulheres & 37 \\
\hline Homens & 33 \\
\hline Mulheres e homens & 30 \\
\hline Profissionais/gestores & 30 \\
\hline Pessoas trans/HSH & 4 \\
\hline Total & $134^{\star}$ \\
\hline \multicolumn{2}{|l|}{ Temas } \\
\hline Violência baseada no gênero (VBG) & 32 \\
\hline Masculinidades/saúde dos homens/ PNAISH & 32 \\
\hline Saúde Sexual e reprodutiva (contracepção, atenção ao parto, violência obstétrica, HIV/aids e outros) & 19 \\
\hline Aborto & 16 \\
\hline Sexualidade & 15 \\
\hline Gênero e Saúde & 13 \\
\hline Trabalho & 10 \\
\hline Políticas Publicas & 7 \\
\hline Saúde mental/uso de substâncias & 7 \\
\hline Gênero e violência & 4 \\
\hline Gênero e poder & 4 \\
\hline Envelhecimento & 3 \\
\hline Outros & 2 \\
\hline Total & $164^{*}$ \\
\hline Abordagem metodológica & $\mathbf{N}$ \\
\hline Qualitativa & 64 \\
\hline Quantitativa & 46 \\
\hline Total & $110^{*}$ \\
\hline
\end{tabular}

${ }^{\star}$ Os totais incluem apenas os estudos aos quais esta classificação se aplica. 
cente, como a saúde dos homens e as masculinidades, objeto de publicação pioneira em 2005 (vol 10, n 1), ou incorporação da categoria gênero na análise dos processos saúde-doença, em 2009 ( $v 14, \mathrm{n} 4$ ). Entretanto, o pioneirismo da C\&SC na abordagem do tema gênero e saúde já se apresentava desde 1999 com a publicação de uma revisão sobre políticas de enfrentamento à violência doméstica, contra mulheres ${ }^{26}$, em número sobre violência (vol 4, n1). Este tema teve destaque na Plataforma de Direitos Humanos da Organização das Nações Unidas (Viena, 1993) ${ }^{27}$ e antecedeu as afirmações sobre o direito à saúde sexual e reprodutiva presentes na Plataforma do Cairo e Beijing.

Tomando-se as conferências da ONU como balizadores de políticas públicas e produções acadêmicas, percebe-se que a VBG assume caráter específico em relação às demais formas de violência e agravos a saúde marcados pelas desigualdades de gênero. Esta especificidade se reflete na intensa produção sobre o tema e na reiterada problematização da VBG nos serviços de saúde. De fato, embora haja consenso sobre as repercussões negativas da VBG para a saúde das mulheres, este não necessariamente tem se traduzido em respostas eficazes ${ }^{28}$. Sendo uma das piores manifestações das desigualdades de gênero, a violência parece resistir às ações de prevenção ou enfrentamento. Publicar textos que abordam a questão sob diferentes ângulos, contribui para torná-la mais visível, rompendo o pacto de silencio em torno do assunto e contribuindo com a busca de soluções.

Os dois primeiros trabalhos com o termo "gênero" datam de 2002 e foram publicados num número temático sobre informação e saúde ${ }^{29,30}$ centrados numa análise de dados da PNAD, procuram dar visibilidade às inequidades de gênero na saúde como um subsídio para a implementação de políticas públicas visando à equidade.

A publicação do volume "Homens como foco para a saúde pública” (2005, vol. 10, nº1) assume que a inserção social dos homens também é marcada pelo gênero. Assim, é necessário investigar como as normas de gênero afetam a saúde dos homens. Anunciando este posicionamento, em 2003 foi publicada uma reflexão sobre a prevenção do câncer da próstata e o imaginário "generificado" a respeito da sexualidade masculina ${ }^{31}$. A saúde dos homens volta a ser problematizada em número sobre a Política Nacional de Atenção Integral à Saúde dos Homens (2012, vol.17, $\mathrm{n}^{\circ} 10$ ), no qual o conjunto dos artigos ilustra a reprodução das normas de gênero nas instituições, representações e práticas sociais. As discussões sobre os desafios da incorporação dos homens nas ações básicas de atenção à saúde, tradicionalmente voltadas para as mulheres e as crianças, são retomadas em volumes subsequentes.

A desconstrução das normas de gênero responsáveis pelo aumento dos riscos à saúde dos homens é bastante polemizada, dado que os supostos atributos que colocam os homens em risco são os mesmos que lhes conferem poder ${ }^{32}$. A análise das hierarquias existentes entre os homens, em função de classe social, raça/etnia, orientação sexual, por exemplo, é a chave para desconstruir a ideia de um "poder" imanente ${ }^{33}$. Assim, cabe compreender os homens e suas masculinidades a partir das normas de gênero, e não apenas sob o ângulo da dominação das mulheres. Ou seja, o estudo das masculinidades e suas repercussões para a saúde adquirem legitimidade na saúde coletiva e no estudo das repercussões, para a saúde das mulheres, das normas que instituem as feminilidades ${ }^{34}$.

Quanto aos números temáticos, cabe mencionar o volume sobre a incorporação de gênero na saúde coletiva $\left(2009\right.$, vol. $\left.14, n^{\circ} 4\right)$, que aponta a potencialidade do uso desta categoria no campo da saúde coletiva e atualiza estudo de revisão publicado $^{21}$. Este volume foi organizado pelo Grupo Temático Gênero e Saúde da Associação Brasileira de Saúde Coletiva, Abrasco, editora da C\&SC. O GT foi criado em 1995 com "a finalidade de contribuir com o ensino e a produção do conhecimento sobre os impactos das desigualdades sociais entre homens e mulheres na saúde" 35 . Sua intensa participação nas publicações e nos eventos promovidos pela Abrasco revela a pertinência da sua proposta. $\mathrm{O}$ volume organizado pelo GT Gênero e Saúde confirma ainda a sensibilidade e a abertura da Abrasco e da C\&SC para novos olhares sobre a realidade e o compromisso político com a promoção da equidade de gênero.

O número temático sobre aborto (2012, vol. $\left.17, n^{\circ} 7\right)$ reitera essa sensibilidade e comprometimento. Sendo uma prática criminalizada e fortemente estigmatizada, a publicação de dados, experiências e análises sobre o aborto, é fundamental para desfazer mitos e preconceitos que impedem o acesso das mulheres, especialmente das mais pobres, a métodos seguros de interrupção de uma gravidez indesejada ou inoportuna. A importância deste número temático fica sublinhada quando se constata que 14, dos 16 artigos sobre aborto publicados na C\&SC, foram incluídos neste volume.

Mesmo levando em conta a edição de volumes temáticos sobre temas permeáveis às análi- 
ses de gênero, o perfil dos temas é semelhante ao apontado em outras revisões ${ }^{36}$. A multiplicidade de temas e grupos populacionais investigados reflete os desdobramentos semânticos que a categoria gênero foi adquirindo à medida da sua incorporação aos estudos acadêmicos. Assim, é possível identificar ecos das diferentes matrizes teóricas que marcam a construção e o uso desta categoria, tais como: o foco privilegiado nas mulheres e nos processos de dominação pelos homens, o desvendamento das tramas de poder que subjuga homens e mulheres, por meio da criação de antagonismos, as análises sobre o imbricamento entre corpo, sexualidade e subjetividade na (re)produção e transformação das normas de gênero.

Refletindo esta multiplicidade teórica, a produção analisada reafirma que gênero não se refere apenas a mulheres e que não é apenas no âmbito da saúde sexual e reprodutiva, do exercício da sexualidade e da exposição à violência que ele impacta a saúde. Todas as dimensões da vida, incluindo o trabalho, a saúde mental, os estilos de vida e o uso de substâncias são afetados pelo gênero. A produção de manuscritos sobre estes temas, ainda que mais tímida, expressa outras possibilidades de uso da categoria gênero na saúde coletiva.

No que se refere às lacunas, apesar do esforço da revista em dar visibilidade às experiências dos sujeitos ao longo dos ciclos da vida, poucos trabalhos aprofundam esta questão, seja em relação às pessoas idosas ou aos jovens e aos adolescentes. Muitos estudos com grupos nas fases não reprodutiva da vida não discriminam as experiências dos sujeitos femininos, masculinos ou trans. Os artigos voltados para a população adolescente ou jovem, em geral, se referem à sexualidade ou reprodução, como se as desigualdades de gênero reverberassem apenas nessas esferas.

Foi observada ainda a escassez de trabalhos explorando a interseccionalidade entre os marcadores sociais de desigualdade. Embora alguns artigos façam referência à inserção social, laboral ou étnico/racial dos sujeitos, falta uma reflexão mais densa sobre a sinergia entre as diferentes situações de desigualdade, ou mesmo a sua potencialidade na produção de formas de enfrentamento ou resiliência. Tal ausência, em parte, pode ser atribuída ao desafio teórico metodológico trazidos por esta perspectiva ${ }^{37}$.

\section{Comentários finais}

O que é publicado em uma revista depende, dentre outros aspectos, do que é submetido. Assim, as lacunas identificadas apontam mais para as apropriações que os autores fazem da categoria gênero do que de um posicionamento da revista. Cabe salientar que a C\&SC, ao longo do tempo, se mostrou ativa em propor temas inovadores, especialmente pela edição de números temáticos relacionados ao gênero. A resposta dos pesquisadores aos números temáticos demonstra a oportunidade da iniciativa. A existência de uma editoria de gênero e a presente publicação no âmbito dos 25 anos da revista, reforçam esta postura.

As reflexões e as diretrizes políticas globais ${ }^{9,11-13}$ assinalam a pertinência e a relevância de que a perspectiva de gênero permeie cada vez mais a análise dos dados de pesquisa em diferentes temas. Nesse sentido, é importante que a C\&SC mantenha a sua aposta na vitalidade da abordagem de gênero e na inquirição de novos objetos e aportes teóricos, capazes de iluminar a compreensão e o enfrentamento das desigualdades em saúde. Ilustra essa perspectiva o destaque da ONU mulheres ${ }^{38}$ sobre o impacto da recente pandemia do Covid-19 na população feminina. A agência internacional salienta que, a despeito das graves implicações socioeconômicas da pandemia para todos os segmentos populacionais, é preciso reconhecer que ela impacta de modo diferenciado homens e mulheres. Tais diferenças devem ser consideradas nas ações de controle, prevenção e cuidado, analisadas e publicizadas em periódicos de escopo amplo como a C\&SC. 


\section{Colaboradores}

WV Villela e SS Monteiro participaram igualmente da concepção do trabalho, seleção e análise de material e elaboração do manuscrito. RM Barbosa participou da elaboração do manuscrito e revisão final.

\section{Referências}

1. Rubin G. The traffic in women: Notes on the "political economy" of sex. In: Reiter R, editor. Toward an Anthropology of Women. New York: Monthly Review Press; 1975. p. 157-210.

2. Rubin G. Thinking sex: Notes for a radical theory of the politics of sexuality. In: Nardi PM, Schneider BE, editors. Social perspectives in Lesbian and Gay Studies; A reader. Hove: Psychology Press; 1984. p. 100-133.

3. Scott JW. Gender: a useful category of historical analysis. The American historical review 1986; 91(5):10531075.

4. Butler J. Gender Trouble. London: Routledge; 1990.

5. Butler J. Bodies that Matter. London: Routledge; 1993.

6. PiscitellI A. Gênero: a história de um conceito. In Almeida H, Szwako JE, organizadores. Diferenças, igualdade. São Paulo: Berlendis \& Vertecchia; 2009. p. 116-148.

7. Crenshaw K. Demarginalizing the Intersection of Race and Sex: A Black Feminist Critique of Antidiscrimination Doctrine, Feminist Theory, and Antiracist Politics. The University of Chicago Legal Forum, Chicago; 1989; p. 139-167.

8. Sardenberg CM. Caleidoscópios de gênero: gênero e interseccionalidades na dinâmica das relações sociais. Mediações - Revista de Ciências Sociais 2015; (20):5696.

9. Danylova TV, Kats LA. "All animals are equal, but some animals are more equal than others": The negative impact of gender inequality on the global economy and public health. Anthropological Measurements of Philosophical Research 2019; (15):101-110.

10. Aquino EM. Gênero e saúde: perfil e tendências da produção científica no Brasil. Rev Saude Publica 2006; 40(n. esp.):121-132.

11. Oksuzyan A, Dańko MJ, Caputo J, Jasilionis D, Shkolnikov VM. Is the story about sensitive women and stoical men true? Gender differences in health after adjustment for reporting behavior. Soc Sci Med 2019; 228:41-50.

12. Calzo JP, Katz-Wise SL, Charlton BM, Gordon AR, Krieger N. Addressing the dearth of critical gender analysis in public health and medical pedagogy: an interdisciplinary seminar to generate studentcreated teaching examples. Critical public health 2019; 29(1):18-26.

13. Hay K, McDougal L, Percival V, Henry S, Klugman J, Wurie H, Dehingia N. Disrupting gender norms in health systems: making the case for change. Lancet 2019; 393(10190):2535-2549.

14. Fundo de População das Nações Unidas (UNFPA). Conferência Internacional sobre População e Desenvolvimento. Plataforma de ação. Cairo: UNFPA; 1984.

15. Doyal L. The politics of women's health: setting a global agenda. Int J Health Serv 1996; 26(1):47-65.

16. Mulheres O.N.U. Declaração e Plataforma de Ação da IV Conferência Mundial sobre Mulheres. Brasília: UNFPA Brasil; 1995.

17. United Nation (UN). Economic UN, Council S. Coordination of the Policies and Activities of the Specialized Agencies and Other Bodies of the United Nations System: Mainstreaming the Gender Perspective into All Policies and Programmes in the United Nations System, Report of the Secretary-General. New York: UN; 1997. (UN Doc. E/1997/66) 
18. Morgan R, George A, Ssali S, Hawkins K, Molyneux S, Theobald S. How to do (or not to do)... gender analysis in health systems research. Health Policy Plan 2016; 31(8):1069-1078.

19. Osis MJ. Paism: um marco na abordagem da saúde reprodutiva no Brasil. Cad Saude Publica 1998; 14(Supl.):S25-S32.

20. Carrara S. Comentários diagonais sobre a emergência dos homens na pauta da Saúde Coletiva. Cien Saude Colet 2005; 10(1):28-29.

21. Pinto L, Oliveira I, Pinto E, Leite C, Melo A, Denys M. Políticas públicas de proteção à mulher: avaliação do atendimento em saúde de vítimas de violência sexual. Cien Saude Colet 2017 22(5):1501-1508.

22. Villela W, Monteiro S, Vargas E. A incorporação de novos temas e saberes nos estudos em saúde coletiva: o caso do uso da categoria gênero. Cien Saude Colet 2009; 14(4):997-1006.

23. Osmo A, Schraiber LB. O campo da saúde coletiva no Brasil: definições e debates em sua constituição. Saúde Soc 2015; 24(Supl.):205-218.

24. Hammarström A, Hensing G. How gender theories are used in contemporary public health research. Int J Equity Health 2018; 17(1):34.

25. Canesqui, AM. Temas e abordagens das ciências sociais e humanas em saúde na produção acadêmica de 1997 a 2007. Cien Saude Colet 2010; 15(4):1955-1966.

26. Cavalcanti ML. Prevenção da violência doméstica na perspectiva dos profissionais de saúde da família. Cien Saude Colet 1999; 4(1):193-200.

27. Facio A. Viena 1993, cuando las mujeres nos hicimos humanas. Pensamiento iberoamericano 2011; 9:3-20.

28. Garcia-Moreno C, Amin A. Violence against women: where are we 25 years after ICPD and where do we need to go? Sex Reprod Health Matters 2019; 27(1):13.

29. Pinheiro R, Viacava F, Travassos C, Brito A. Gênero, morbidade, acesso e utilização de serviços de saúde no Brasil. Cien Saude Colet 2002; 7(4):687-707

30. Romero DE. Diferenciais de gênero no impacto do arranjo familiar no status de saúde dos idosos brasileiros. Cien Saude Colet 2002; 7(4):777-794.

31. Gomes R. Sexualidade masculina e saúde do homem: proposta para uma discussão. Cien Saude Colet 2003; 8(3):825-829.
32. Matthews CR, Channon A. The 'male preserve' thesis, sporting culture, and men's power. 2019. [acessado 2020 Mar 30]. Disponível em: http://irep.ntu.ac.uk/ id/eprint/35611/1/13047_Matthews.pdf

33. Medrado B, Lyra J. O gênero dos/nos homens: linhas de uma proto-genealogia. Cien Saude Colet 2012; 17(10):2579-2581.

34. Bermúdez M. Connel y el concepto de masculinidades hegemónicas: notas críticas desde la obra de Pierre Bourdieu. Revista Estudos Feministas 2013; 21(1):283300.

35. Associação Brasileira de Saúde Coletiva (Abrasco). GT Gênero e Saúde. 2020. [acessado 2020 Mar 30]. Disponível em: https://www.abrasco.org.br/site/gtgeneroesaude/

36. Araújo MF, Schraiber LB, Cohen D. Penetração da perspectiva de gênero e análise crítica do desenvolvimento do conceito na produção científica da Saúde Coletiva. Interface (Botucatu) 2011; 15(38):805-818.

37. Migliorini L, De Piccoli N. Challenging gender perspective in the community to promote well-being and health. J Prev Interv Community 2019; 48(2):121-131.

38. Organização das Nações Unidas (ONU Mulheres). Mulheres e COVID-19: cinco coisas que os governos podem fazer agora. Brasil. 2020. [acessado $2020 \mathrm{Abr}$ 4]. Disponível em: http://www.onumulheres.org.br/ noticias/mulheres-e-covid-19-cinco-coisas-que-osgovernos-podem-fazer-agora/

Artigo apresentado em 19/05/2020

Aprovado em 27/05/2020

Versão final apresentada em 29/05/2020 